\title{
Sobre la reconversión industrial
}

\author{
Joaquín Arriola
}

\section{Industrla y desarrollo}

Se ha convertido en tradición de debate en el pais, al hablar de desarrollo, centrar el análisis en el campo. Ciertamente, la mayor parte de las divisas por comercio de mercancias, y toda la estructura de poder, se articulan en torno al campo, sea en lo económico (el poder de la oligarquia), lo social (la influencia de las cooperativas) o lo político (las zonas de conflicto armado).

Sin embargo, el desarrollo no se puede concebir centrado en la expansión de las actividades agrícolas. La esencia del desarrollo histórico del capitalismo se concreta en enormes ganancias de productividad, en la capacidad social de multiplicar los excedentes con los mismos recursos de trabajo (es decir, el paso de una acumulación predominantemente extensiva a otra de predominio intensivo). En el centro de atención debe situarse por tanto la industrialización, entendida como la transformación de la naturaleza en mercancias que emplean trabajo de creciente complejidad.

En las estimaciones más optimistas, la transformación de las explotaciones agrarias de este pais en unidades capitalistas, es decir, capaces de producir un excedente suficiente para reproducir la fuerza de trabajo asalariada y no asalariada y abastecer las necesidades de consumo de la población urbana, a través de un importante aumento de la productividad que permita eliminar la agricultura de subsistencia, exige una dimensión mínima por unidad familiar de 8-10 ha. con tecnología tradicional y 4-5 ha. con uso de insumos mejorados, lo cual se traduce en la existencia de una sobrepoblación en actividades agricolas de entre 330,000 y 160,000 familias, por cuanto una distribución igualitarlsta de la tierra otorgaría a cada familia campesina una parcela de tan solo 2.7 ha.' El problema entonces radica no tanto en el agro, cuanto on la 
falta de dinamismo de la economia para generar una demanda de fuerza de trabajo suficiente para absorber dicho excedente de mano de obra agraria: el problema de la economia salvadorena no es el campo -aunque ahi se manifiesten las principales contradicciones socialessino la urbe: la industria y los servicios.

Cuando la nueva fuerza de trabajo salvadorena se utiliza para producir plusvalía en los Estados Unidos o en el sector informal, el objeto de reproducir a un menor costo la (escasa) fuerza de trabajo empleada directamente por el capital (subsunción indirecta), hay que concluir que la dinámica del capital en el país se mueve por una lógica que no implica la valorización interna del capital: la fórmula D-M-D', que en los Estados Unidos sería \$-M-\$, o en Alemania DM-MD-M, en El Salvador

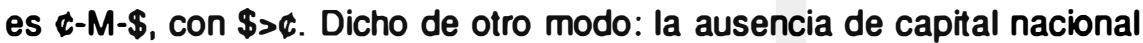
(moneda convertible) se expresa en forma de extraversión de la economia y de transformación y de producción capitalista de servicios que de todos modos exigen un desarrollo capitalista del aparato estatal imposible en la actual dinámica de la economia.

Es en este marco en él que se debe analizar no solo los límites de la política económica del gobierno, sino también la dinámica que genera en la economía, que adelantamos, es una dinámica que refuerza la integración de la producción de mercancias en el país en los circuitos internacionales de valorización del capital (en xeno-dólares).

La intervención estatal en la regulación económica es imprescindible, aunque sus modalidades puedan ser objeto de variación significativa, en función de la coyuntura político-social y el modelo de desarrollo que se esté implementando. En cualquier caso, las funciones del estado en la regulación económica del crecimiento las podemos caracterizar en dos dimensiones ${ }^{2}$ : una función de regulación coyuntural del crecimiento, mediante el uso de las políticas monetarias y presupuestarias (fiscal o de ingresos y el gasto público), y un instrumental de medición basado esencialmente en la Contabilidad Nacional y determinados indicadores de coyuntura referidos a la economia monetaria (índice de precios y saldo de cuentas con el exterior).

Más allá de esa intervención coyuntural, el Estado participa siempre en la estrategia de crecimiento de la economia con tres funciones de tipo estructural: a) una función de apoyo logístico del crecimiento, favoreciendo a la industria privada y al desarrollo de las fuerzas productivas mediante la financiación pública de las infraestructuras, comunicaciones, investigación e inversiones sociales, to cual significa la socialización de una fracción de los costos de producción; b) una función de intervención estructural sobre la producción y la distribución, bien de tipo 
interno, favoreciendo la modemización, la concentración y en caso de necesidad, asumiendo la nacionalización de capitales desvalorizados, 0 bien de tipo extemo, mediante tratados (GATT), instituciones de dominio y de reproducción de la jerarquía de los sistemas productivos (FMI) o procesos de integración que facilitan espacios de valorización ampliados (CEE); e) en tercer lugar, el Estado ejerce una función de regulación por las políticas de desarrollo, especialmente las políticas sectoriales de intervención selectiva. La "política industrial" es el ejemplo más desarrollado de las mismas; precisamente la ausencia histórica de políticas industriales en los EE. UU., es una de las principales diferencias con las políticas seguidas en Japón y en Alemania, y una de las principales explicaciones del peor comportamiento de la economia norteamericana en la actual coyuntura de crisis, de sus mayores dificultades para reestructurar su aparato productivo mediante ganancias significativas de productividad.

\section{La Industria en la politica econónica del goblerno}

En el caso de El Salvador, se constata en el programa del gobierno de ARENA un vacio relativo de propuestas estructurales, que se transforma en cero absoluto en materia de políticas de desarrollo, en el sentido arriba comentado. Su plan de desarrollo económico ${ }^{3}$ es un mero programa de gestión de coyuntura: del denominado "plan quinquenal de inversiones públicas", que en todo caso se prevee no sobrepase al 3 por ciento del PIB nominal en los cinco años, se nos dice que "solo el 3.5 por ciento de la inversión pública requerida para el quinquenio está financiada." Por otro lado, en el denominado "plan de desarrollo social" el 100 por 100 de la inversión prevista se genera con recursos extemos (fundamentalmente AID y Programa Mundial de Alimentos), aunque por el momento la situación es que solo se ha logrado financiación para el 5 por ciento del monto total, estando "en negociación" un 59.3 por ciento, faltando por tanto la fuente identificable para la financiación del 35.7 por ciento de la inversión social que pretende llevar a cabo el gobierno ${ }^{4}$ cuando falta por conseguir los recursos financieros para jel 96.5 por ciento dela inversión pública prevista!, que por otro lado sobrepasaría escasamente el 3 por ciento del PIB nominal en un contexto además de reducción del presupuesto púbico para 1991 en términos reales, cualquier referencia a políticas estructurales o políticas de desarrollo es pura palabrería, cuyo simple comentario va en demérito del carácter analítico de nuestra investigación.

Esta ignorancia por parte del gobierno y de sus asesores economicos respecto a los requerimientos de una política de desarrollo que contemple una política especifica para el sector industrial se refleja on 
otro documento del gobierno, que al valorar en 58 páginas la evolución de la coyuntura semestral en el pais, tan solo dedica jun párrafol al análisis de la coyuntura en el sector industrial.

Estas carencias no son fruto de la casualidad, por el contrario reflejan el verdadero carácter de las fuerzas dominantes en el gobiemo del pals: los sectores del capital exportador (agricola e industrial), que realizan la valorización del capital a través de la conversión de las mercanclas salvadorenas en monedas convertibles: maximizar la restabilidad significa minimizar la metarmofósis de capital dinerario en mercancía (D-M) y maximizar la metamóriosis de la mercancia en capital dinerario (M-D'), que en el caso de un pais sin moneda convertible como es el nuestro, de escasas dimensiones y con un mercado potencial para la realización de las mercancias capitalistas de sólo un tercio de la población total, se traduce en una reducción al mínimo de la circulación interna del capital. Cuando además las principales mercanclas de exportación, al margen de la fuerza de trabajo, son productos agropecuarios con un escaso componente revalorizador de la fuerza de trabajo (cualificación requerida, estabilidad laboral, o complejidad del proceso de producción, todo ello va en detrimento de las posibilidades que tienen los trabajadores agropecuarios para elevar el precio de su fuerza de trabajo) el modelo que se diseña es claro: inversiones públicas sólo en las infraestructuras que canalizan la circulación de mercancias al exterior (electricidad, telecomunicaciones, puertos y aeropuertos), reducción al mínimo requerido para el mantenimiento del orden público de la parte de la plusvalia transformada en gasto social por tanto reducción de impuestos sobre el capital y reducción del gasto público. La lógica de la liberalización en El Salvador no obedece, como en los paises desarrollados, a la necesidad de recuperar espacios para la valorización del capital, convirtiendo en objeto de centralización y concentración del capital y de conversión en mercancias de múltiples actividades bajo gestión pública, sino más bien a la orientación extravertida del capital local, dominado por la necesidad de valoración internacional, como lo expresa la carencia de moneda convertible.

En estas circunstancias, la ausencia de una política de desarrollo industrial es consecuencia de la ausencia de la función reguladora del crecimiento por parte del Estado, al que se asigna una mera función de regulación del orden social establecido. Estado y desarrollo industrial están inextricablemente unidos en todas las experiencias nacionales conocidas de desarrollo por la industrialización, incluso en el tan manido caso chileno, donde la principal actividad generadora de divisas (el cobre) cuya nacionalización por el gobierno de la Unidad Popular desató la campana de desestabilización que acabó en el golpe de Estado, 
no fue nunca reprivatizada por el gobierno de la dictadura militar.

\section{La coyuntura de la Industrla salvadorefia}

La evolución de los indicadores del sector manufacturero en EI Salvador refleja una situación de crisis estructural, más profunda que la propia situación coyuntural de deterioro económico general de la última década: en 1986 el empleo en el sector sólo era el 80.2 por ciento del existente en 1978, mientras que el valor anadido se redujo en el mismo período hasta el 76.4 por ciento; el relativamente mayor deterioro de la producción agregada del sector respecto a la evolución del empleo refleja una caida en la productividad aparente: si en 1978 la producción por empleado se situaba en unos 12.000 colones anuales, en 1986 se redujo hasta los 11.400 (en colones de 1962).

La industria manufacturera no ha tenido el efecto dinámico de arrastre que va implicito en todo proceso de desarrollo: su participación en la actividad productiva total disminuyó en la década de los setenta pasando de representar el 18.6 por ciento del conjunto de actividades mercantiles en la primera mitad de los $70^{\prime} \mathrm{s}$, al 15.3 por ciento en la segunda mitad de los setenta, recuperándose parcialmente en la primera mitad de los ochenta, donde la manufactura alcanza un 17.5 por ciento de participación todavia en 1987, el valor agregado en precios constantes de la industria manufacturera era inferior al logrado en 1974; al finalizar la década de los ochenta, no se habia logrado recuperar el valor agregado alcanzado en el sector al finalizar la década anterior.

- Este escaso dinamismo del sector se observa antes de la grave crisis de los ochenta:

En la primera mitad de los sententa, la producción manufacturera creció a una tasa de solo el $\mathbf{8 1}$ por ciento de la alcanzada por el PTB, mientras que entre 1975 y 1979 sólo alcanzó el 48.3 por ciento de la tasa de crecimiento del producto global.

Ciertamente, la pérdida del mercado común centroamericano supuso un duro golpe para una industria orientada básicamente al mercado regional. Pero ésto no explica toda la crisis del sector anterior y posterior a la década de los ochenta. Si tenemos en cuenta que en los últtimos anos los productos de exportación no tradicionales de mayor envergadura son precisamente productos industriales y no agricolas (sobre todo, productos farmacéuticos y textiles - totales-), somrende observar que el deterioro relativo del sector químico es áun más grave que el de la industria en su conjunto. 
Varlación anual en \% (preclos corrlentes)

\begin{tabular}{lrrr}
\hline & $\begin{array}{r}\text { PTB } \\
(1)\end{array}$ & $\begin{array}{c}\text { MANUF. } \\
(2)\end{array}$ & $\begin{array}{c}(2) /(1) \\
\%\end{array}$ \\
\hline 1970 & 8.0 & 4.0 & 50.0 \\
1971 & 5.2 & 7.1 & 136.5 \\
1972 & 6.6 & 8.3 & 125.8 \\
1973 & 15.6 & 8.5 & 54.5 \\
1974 & 18.4 & 15.7 & 85.3 \\
1975 & 13.5 & 17.7 & 131.1 \\
1976 & 26.8 & 11.1 & 41.4 \\
1977 & 25.6 & 12.2 & 47.7 \\
1978 & 7.3 & 15.1 & 206.8 \\
1979 & 11.9 & 11.0 & 92.4 \\
1980 & 3.6 & 0.1 & 2.8 \\
1981 & -3.0 & 1.5 & \\
1982 & 3.7 & 1.7 & 45.9 \\
1983 & 13.2 & 13.8 & 104.5 \\
1984 & 14.8 & 16.9 & 114.2 \\
1985 & 22.9 & 27.7 & 121.0 \\
1986 & 37.9 & 31.5 & 83.1 \\
1987 & 17.1 & 31.1 & 181.9 \\
1988 & 18.2 & 18.8 & 98.9 \\
\hline
\end{tabular}

$\%$ en el total de manufacturas

\begin{tabular}{l|rrr}
\hline & quimicos & toxtiles & p. alimenticlos \\
\hline 1970 & 7.7 & 13.1 & 28.7 \\
1971 & 8.3 & 13.1 & 28.2 \\
1972 & 8.3 & 12.9 & 28.4 \\
1973 & 8.2 & 13.0 & 28.0 \\
1974 & 8.5 & 12.4 & 26.3 \\
1975 & 8.4 & 10.0 & 30.9 \\
1976 & 8.4 & 10.0 & 30.9 \\
1977 & 9.0 & 9.8 & 28.6 \\
1978 & 9.4 & 10.1 & 27.6 \\
1079 & 8.4 & 9.1 & 29.2 \\
1980 & 5.3 & 8.6 & 32.0 \\
1981 & 5.0 & 7.7 & 32.0 \\
1982 & 5.6 & 5.6 & 33.3 \\
1983 & 6.3 & 5.9 & 33.2 \\
1984 & 6.1 & 6.2 & 34.9 \\
1985 & 5.4 & 4.9 & 36.2 \\
1986 & 5.6 & 6.1 & 36.4 \\
1987 & 5.3 & 5.7 & 36.2 \\
1988 & 5.0 & 5.7 & 37.8 \\
\hline
\end{tabular}


En los anos ochenta, la industria quimica tiene una importancia relativa dentro del sector manufacturero en torno a un $\mathbf{4 0}$ por ciento inferior a la década anterior.

Por otro lado, las industrias alimentarias representan más de un tercio de la producción manufacturera total. Podría pensarse en un cierto desarrollo "río abajo" en la agroindustria, pero más bien nos encontramos ante una rama dedicada a la fabricación de productos alimenticios de lujo: salsas, pastas, etc. o de empaquetado (derivados lacteos). La carencia en el desarrollo de una agroindustria en las ramas situadas "río arriba" de la actividad agricola (química, maquinaria) es casi absoluta, como lo demuestra la propia evolución del sector quimico.

\section{Algunas Ideas sobre la reconversion Industrlal}

La expresión "reconversión industrial" tiene su origen en las políticas llevadas a cabo por diferentes paises desarrollados, en especial europeos, que se encuentran, en un marco de transnacionalización acelerada de los sistemas productivos y de competencia renovada en determinadas ramas tradicionales por la aparición de nuevos competidores (Corea, Brasil o Japón) a los cuales no se puede hacer frente con una tecnología poco renovada y unos costes salariales y financieros crecientes.

La reconversión industrial consiste en un proceso dinámico de identificación de limitantes, evaluación y propuestas y actuaciones en materia de política industrial, en dos fases: una de concentración de recursos en reducción de capacidades instaladas, renovación tecnológica y saneamiento financiero, y una segunda, de ampliación y diversificación de actividades, orientando los recursos públicos hacia las ramas y actividades que se consideren más dinámicas, con mayores efectos externos positivos, dentro de un plan de desarrollo en el cual se contemple una política industrial orientada a dinamizar la economia. Esta segunda fase se denomina de "reindustrialización".

Requisitos indispensables de toda política de reconversión son:

a) Voluntad política de llevarla a cabo -que implica asumir los costes políticos de los aspectos impopulares de la misma, como son reducciones de capacidad de empleo y de crecimiento de salarios.

b) Financiación adecuada. Toda política de reconversión exige fondos financieros en grandes cantidades. El incremento y la reorientaclón del gasto público aparecen como una condición imprescindlble de la reconversión. 
c) Negociación. La reconversión no se puede llevar a cabo si no cuenta con la posibilidad de lograr el acuerdo de los sindicatos y empresarios: garantizando que los trabajadores afectados tendrán algún tipo de garantía laboral (recolocación) o de subsidio de desempleo, se puede negociar la reducción del empleo; creando las condiciones para que los empresarios afectados por la reconversión tengan acceso a financiación en condiciones ventajosas, se puede lograr que estos acepten la inevitable coordinación del Estado en la planificación y diseno del nuevo escenario industrial del pais.

Ahora bien: en contexto de ajuste recesivo, con un gobiemo deslegitimado ante grandes sectores de la población, un presupuesto nacional decreciente y un marco de concertación laboral inexistente, actualmente no se cumplen en El Salvador ninguno de los requisitos previos a cualquier reconversión industrial.

Una clave de éxito en cualquier proceso reindustrializador es "la capacidad del gobierno para modificar el entorno de las firmas industriales, de modo que reduzcan el riesgo que perciben, y disminuyan la tasa de rentabilidad minima exigida a las inversiones. De esa manera se espera alejar el horizonte prospectivo de las empresas y volver más rentable la inversión productiva que la inversión especulativa.. ${ }^{\text {"b }}$

En el caso de nuestro pais, los factores de riesgos son más complejosque en otros paises de estructura social y económica similar:

a) La guerra. Sin duda, la existencia de un conflicto de clases tan agudizado como el que se vive en El Salvador desde hace más de una década es el principal desmotivador para la realización de inversiones productivas. El problema se complica cuando lo que se produce es más bien un proceso de desinversión. La importancia de este fenómeno queda parcialmente reflejado en los datos cuantitativos arriba senalados, pero el problema va más allá: lo que se está produciendo en la última década es un proceso de pérdida de cultura industrial, tanto por parte de los trabajadores como de los inversionistas; aquellos aspiran a trabajar en el sector servicios, o en tareas administrativas. Estos, se dedican a la especulación o al comercio. "Los salvadorefios nos estamos especializando en pedir, comprar y vender", acertada frase del Dr. Eduardo Badia, que refleja adecuadamente el deterioro de las potencialidades productivas del sistema social salvadoreno.

b) El tamaño del mercado: es otro factor que desincentiva la producción industrial. La extrema polarización en la distribución de la renta hace que el mercado real para productos manufacturados sea aun más reducido de lo que potencialmente permitiria la renta disponible 
per cápita. Si a esto anadimos la ausencia de integración regional, se concluye fácilmente que el mercado disponible impide la generación de las economias de escala requeridas por la mayor parte de las actividades industriales modernas, abocando a las escasas industrias existentes a la exclusiva orientación exportadora, lo cual supone una desventaja comparativa, frente a las producciones de aquellos paises que, ceteris paribus, disfrutan de mejores rentas de localización (México, Puerto Rico, R. Dominicana), o pueden disf́ntar de las economias de escala que les da un mercado interno de dimensiones adecuadas. Un singular estudio nos sefiala que los pequenos paises sólo alcanzan la escala óptima de producción, dada su magnitud de mercado, para la fabricación de tejidos de algodón y zapatos; el mercado regional centroamericano permitiria alcanzar las economias de escala para la producción por ejemplo de cenveza, gasolina, cemento, acero, harinas, papel para periódicos, ácido sulfúrico, caucho sintético, celulosa, detergentes, bicicletas ${ }^{7}$. No cabe hablar por tanto de reconversión industrial, sin introducir modificaciones en la dimensión y calidad del mercado directo; dicho de otra forma, la reconversión industrial en El Salvador únicamente es viable si va acompanada de medidas efectivas de redistribución de la renta (hacia los sectores de ingresos medios) y de un proceso efectivo de integración regional.

c) La competencia externa: es otro factor de riesgo, cuyas caracteristicas deben ser modificadas en un proceso de reconversión en marcha. La competencia la entendemos en una doble dimensión: la de los productos foráneos en el mercado interior, y la de la producción nacional en los mercados extranjeros. En este sentido, el proteccionismo en los mercados de exportación y la desprotección propia ejercen un efecto agregado en contra de la inversión productiva manufacturera en el pais: una política de incentivación a la producción industrial que respete todas las reglas de la eficiencia y la competitividad, exige un trabajo en los mercados de destino, que a la dimensión de promoción (publicidad) debe anadir necesariamente el trabajo político. En este sentido, cabe recordar que la influencia en los foros internacionales $y$ en las relaciones bilaterales responde a la importancia económica y militar de un país, pero no de forma exclusiva: las carencias en materia de legitimación democrática del gobierno, la falta de un proyecto social y político concertado con la mayoria de la población, debilita la influencia internacional de un país. En este sentido, El Salvador no está en condiciones actualmente de maximizar su influencia potencial, en Europa o los Estados Unidos, en la OEA o el GATT, en orden a lograr modificaciones 
en el Acuerdo Multifibras, mejorar las cláusulas de nación más favorecida, mejorar el acceso político a los circuitos comerciales y mercados, o aunar esfuerzos por lograr una reducción significativa del proteccionismo y del dumping de los principales palses desarrollados.

d) El coste de los insumos: tiene una importancia especial en industrias manufactureras altamente dependientes de las importaciones de bienes intermedios y en general de todo tipo de insumos. Como senalan diversos estudios, la manufactura salvadorena es dependiente de las importaciones incluso en aquellas actividades en las cuales la sustitución de importaciones no parece en principio excesivamente complicadas. El problema es aún mayor cuando el pals, como ocurre en El Salvador, carece de moneda con el carácter de divisa: la incertidumbre cambiaria se vuelve un factor desalentador de las inversiones industriales. Cuando la política económica, como es el caso; tiene un sesgo fuertemente orientado a la exportación de productos que no requieren excesivos insumos importados, ni incorporan mucho valor agregado, y se recurre a la devaluación como instrumento de política, son inevitables las consecuencias de contracción de la demanda interna, incremento de la inflación y lógicamente de desasosiego social todo lo cual va en detrimento del clima adecuado para una elevación de la inversión productiva en el sector industrial.

e) El corte de oportunidad de las actividades manufactureras debemos analizarlo respondiendo a la siguiente pregunta: ¿Cuál es la rentabilidad relativa de la inversión productiva industrial? El incremento de la inversión en la manufactura dependerá en gran medida de la oportuniad de colocar el dinero en actividades más rentables (desde el punto de vista financiero, que no social) ${ }^{2}$. En este sentido, la situación económica depresiva, junto a los factores arriba sefalados, hacen que la especulación con divisas, ciertas actividades comerciales 0 incluso las actividades exportadoras tradicionales sean más rentables desde el punto de vista del capital que las inversiones en actividades manufactureras. Mientras no cambien las expectivas de los inversionistas, la reconversión industrial no puede tener lugar, porque se generaria un vacio de inversiones privadas que bloquearía el proceso.

En definitiva, disenar las líneas maestras de un proceso industrializador requiere profundizar las anteriores reflexiones, a debatir con seriedad, a lo cual pretende colaborar este artículo y la propia revista Realidad, y a lo cual está obligado el propio gobierno. Pero si algo pro- 
meten concluir las ideas vertidas en el artículo, es que sin un Estado regulador, no hay política de reconversión viable.

De nuevo, la responsabilidad del Estado se vuelve irresponsabilidad del gobierno cuando este se escuda en absurdas ideologias liberalistas para sustraerse a sus obligaciones con el desarrollo social del pais.

\section{Notas}

1. Federación Luterana Mundial: La reforma agraria salvadorená, junio 1990. De la superticie total de El Salvador, se estima que el área con vocación agrícola es de un máximo potencial de $1.356 .000 \mathrm{ha}$, mientras que la población del sector agropecuario asciende aproximadamente a unas 500,000 familias.

2. Bernard Rosier: Crecimiento y crisis capitalistas Ed. Labor, Barcelona 1978.

3. Plan de desarrollo económico y social 1989 - 1994. Ministerio de Planiflcación, El Salvador, junio 1990.

4. Op. Cit., págs. 79-80. GAES.

5. "Evolución económico y social": Informe semestral, Miplan, El Salvador, 1990.

6. M. Aglietta y A. Orléan: La violencia de la moneda Siglo XXI, México 1990, pág. 410.

7. Carlos Mackinlay: "Estructura productiva y tamaño de las economias: el caso de las pequeñas economlas latinoamericanas", en Economia de América Latina, núm. 15, 1986 cuadro 11.

8. Francisco Javier Ibisate: "El modelo económico salvadoreño en la matriz insumo-producto: 1978", en Boletin de Ciencias Económicas y Sociales año IX núm. 5, sept.-oct. 1986, pág. 285.

9. Por supuesto, este no es el único determinante de la inversión productiva: la existencia de inversiones previas en una actividad determinan necesariamente un flujo de capital dinerario que deberá seguir transformandose en capital-mercancla. Lo único que determina el coste de oportunidad de la inversión es la tasa a la que se va a realizar dicha acumulación. 